\section{IJ§ER}

ISSN: 2149-5939
International Journal of Social Sciences and Education Research

Online, http://dergipark.gov.tr/ijsser

Volume: 1(1), 2015

\title{
Kaynaştırılmış ders dışı hareket eğitimi ve oyun etkinliğine katılmış sos- yal uyum bozukluğu olan çocukların iki yıl sonraki sosyal uyum süreçleri- nin izlenmesi
}

\author{
The children participated with social adjustment disorders fused extracurricular \\ movement education and game activities monitoring of children's social adaptation \\ process next two years
}

Hulusi Alp ${ }^{1}$

\author{
Hüseyin Çamlıyer²
}

Received Date: $01 / 01 / 2015$
Accepted Date: $01 / 02$ / 2015

\section{$\ddot{0} z$}

Bu araştırmada; ilkokula devam eden, 7-8 yaş aralı̆̆ındaki sosyal uyum bozukluğu gösteren çocuklara uygulanan kaynaştırılmış ders dışı hareket eğitimi ve oyun etkinlikleri programının uygulanmasından iki yıl sonra, çocukların sosyal uyum süreçlerine etkisini incelemek amaçlanmıştır. Araştırma grubu, okul rehber öğretmeni tarafindan belirlenen 25 sosyal uyum ve davranış bozukluğu olan çocukla oluşturulmuştur. Okul rehber öğretmeni tarafindan belirlenen 25 çocuk arasından, araştırmacı tarafindan basit tesadüfi yöntemle seçilen 14 sosyal uyum ve davranış problemi olan çocukla deney grubu, 11 sosyal uyum ve davranış problemi olan çocukla da kontrol grubu oluşturulmuştur. Ölçme aracı olarak, Epir (1974) tarafindan geliştirilen; İlk Okul Çocukları İçin Uyumsal Davranış Ölçeği (Adaptive Behavior Scale) kullanılmıştır. Çocukların 7-8 yaş aralığındaki sosyal uyum süreçleri ile 9-10 yaş aralığındaki sosyal uyum süreçleri karşılaștırılmıștır. Verilerin analizinde, Mann Whitney-U Testi ve Wilcoxon İşaretli Sıralar Testi kullanılmıştır. Sonuçlara olarak; deney grubundaki çocukların izleme test puanlarının kontrol grubundaki çocukların izleme test puanlarından yüksek çıkmasında uygulanan kaynaştırılmış ders dı̧̧ı hareket eğitimi ve oyun etkinlikleri programının iki yıl sonrada etkisinin sürdürdügü görülmüşür. Ayrıca; deney grubundaki sosyal uyum bozukluğu olan çocukların uyumsal süreç izleme puanlarının, kontrol grubundaki çocukların uyumsal süreç izleme puanlarına göre istatistiksel olarak $\left({ }^{*} p<0.05\right)$ ve $\left({ }^{*} p<0.01\right)$ önem düzeyinde anlamlı olduğu saptanmiştır.

Anahtar Sözcükler: İlkokul, Sosyal Uyum, Hareket Eğitimi, Oyun.

\begin{abstract}
In this study; aimed to examine the effects two years after the implementation of social adaptation of children movement education applied fused extracurricular activities and games program. Who attend primary school of the 7-8 age range of children's social adjustment disorder showing. The research group was created with child 25 social cohesion and behavioral disorders, determined by the school counsellor. As determined by the school guidance counsellor 25 children from, was formed by the researchers a simple random randomly selected, 14 social cohesion and behavioral problems of children in the experimental group, 11 social cohesion and behavior problems of children in the control group. Measurement as a means Social Adaptive and Behavior Scale is used who developed by the Adaptive Behavior Scale for Elementary School Children Epirus (1974). Social adaptation process was compared 9-10 years of age in the 7-8 age range of with social adaptation in children. In analyzing the data, Mann-Whitney-U test and Wilcoxon Signed Ranks Test was used. As the results; The children in the experimental group tracking test scores of the children in the control group applied to the high rise in tracking test scores and game fused extracurricular activities, movement education has been shown to maintain the effects of the program after two years. In addition to, with social adjustment disorder in participating in the experimental group children's adaptive process monitoring scores of the children in the control group according to the adaptive process monitoring points statistically significant $(* p<0.05)$ and $(* p<0.01)$ was significant at the significance level respectively.
\end{abstract}

Keywords: Primary School, Social Cohesion, Movement Education, Games

\footnotetext{
${ }^{1}$ University of Suleyman Demirel, ISPARTA/TURKEY, ekim1778@gmail.com

${ }^{2}$ University of Celal Bayar, MANISA/TURKEY, hsyncam@gmail.com
} 
Alp, H., Çamliyer, H. (2015). The children participated with social adjustment disorders fused .....

International Journal of Social Sciences and Education Research, 1 (1), 88-100.

\section{Giriş}

İnsanlar, yaşamı boyunca bir yetişme ve gelişme süreci içindedir (Bilen, 1994). Bu süreçte insanın sürekli olarak çevresindeki insanlarla ilişkileri ve diğer çevre faktörleri sosyal uyumunda önemli rol oynar (Çamlıyer ve Çamlıyer, 2011). Sosyalleşme, toplumda geçerli olan kültürel değerleri öğrenerek, kültürün kuşaktan kuşağa devrini ve bireyin yetişkinlerin dünyasına hazırlanma, yetişkinlerin davranış biçimlerini yaşantısına uygulayabilir duruma gelme anlamına gelmektedir (Tolan, 1996; Bilen, 1994).

Bazı çocuklar, sahip oldukları uyum probleminden dolayı başkalarıyla anlaşmakta zorlanır, uyuşmazlığa düşer, onlardan farklı davranışlar sergilerler; ev, okul ve toplum yaşamı gibi farklı pek çok yaşam alanlarında genel kabul görmüş değer ve kurallara karşı gelme problem davranış örüntüsünün en önemli göstergelerinden olup var olan problemlerden dolayı mutsuz oldukları için çevreyi de olumlu veya olumsuz etkileyebilirler (Azaula, Marsall ve Buck, 2000; Çağlar, 1981; Akt. Özdemir, 2014).

Çocuğun gelişimi açısından kritik yıllar olarak adlandırılan okulöncesi ve ilkokul yıllarında, bir okulöncesi eğitim kurumuna devam eden uyum problemi olan çocuk; akranları arasında, öğrendiği yeni davranışları uygulama fırsatı bulabilecek, uygun sosyal davranışları geliştirmek, toplumda bağımsız yaşam için gerekli becerileri geliştirmesi gerekmektedir (Mark ve Jan, 1995).

Eğitim bireyin toplumsallaşma sürecinde devreye girip, içinde bulunduğu toplumla, birey arasındaki sosyal etkileşime yardımcı olur (Kocayörük, 2000; Çamlıyer 1994). Uyum Problemi Olan çocukların eğitim öğretimlerinde çeşitli boş zaman aktiviteleri uygulanarak düzeltilmeli sonra normal akademik eğitime geçilmelidir. Sportif etkinlikler aracıllı̆ıyla eğitim ve terapi sağlanabilir. Hem kendilerini ifade etme hem de geliştirme imkânı bulurlar (Bayhan, 2005). Hareket eğitimi bu açıdan, çocuğun duyu organları yoluyla dış dünyadan topladığı duyumları değerlendirip psikomotor tepki ve davranış olarak kendini ortaya koyduğu süreçlerde çok etkilidir (Çamliyer, 1994). Hareketlerine ne kadar çok duyu yolunu katarsa ilişkilendirme de o kadar artar ve dolay1sıyla öğrenme düzeyi artar. Hareket programları yoluyla çocuğun, alan, yön, dokunsal beden farkındalığ gelişir ve akademik yetilerin gelişmesinin zeminini oluşturur (Gallahu, 1976). İyi planlanmış bir hareket eğitimi çocuğun diğer çocukların farkına varmasına yardımcı olur ve onlarla uyum içerisinde hareket etme ve işbirliği kurma yeteneğini geliştirir (Özer S. ve Özer K., 2002).

Özel gereksinimli çocuğun, kaynaştırma programına dahil edilmesi için, öncelikle ayrıntılı olarak değerlendirilmesi yani var olan performansının belirlenmesi ve onun için en az kısıtlayıcı eğitim ortamının ne olduğuna karar verilmesi gerekmektedir. Bu, normal gelişim gösteren çocuklarla sadece oyun bahçesini paylaşmadan tüm gün aynı sınıfı ve etkinlikleri paylaşmaya kadar giden farklı kaynaştırma düzeylerinde olabilmektedir. Zira çocuklar arasında etkileşimi teşvik etmeyi amaçlamayan kaynaştırmanın başarısından söz edilemez. Normal gelişim gösteren çocuklarda tutum değiştirme çalışmalarında ise engelli çocuklar ile ilgili filmler, hikâye kitapları, grup tartışmaları, engelli çocuklara ilişkin canlandırmalar ve oyunlar etkili olmaktadır (Tony, 1987; Nancy, 1986).

Oyun bir kültür iletişimi aracının alıştırmalarıdır. Çocuk oyun oynarken kendi çevresindeki araçları kullanır. Oyuncakların, araç ve gereçlerin kullanımı sırasında çocuk vücut organlarını ve kaslarını kontrollü kullanmayı öğrenir. Yaş ilerledikçe çocuklar daha çok başkaları ile birlikte oynamak ve sosyal etkileşim kurmak isterler. Sosyalleşmenin artmasıyla birlikte oyunlar da kar- 
Alp, H., Çamlıyer, H. (2015). Kaynaştırılmış ders dışı hareket eğitimi ve oyun etkinliğine katılmış ..... International Journal of Social Sciences and Education Research, 1 (1), 88-100.

maşıklaşır ve buna bağlı olarak sosyal gelişim arttıkça oyun kurma ve oynama da zorlaşır. Oyunlar yolu ile çocuklar kendileri ve başkaları hakkında bilgi sahibi olurlar, kendi kapasite ve sınırlılıklarını büyüklerle olan farklılıklarını öğrenirler. En önemlisi çocuklar oyunlar yolu ile yaşamlarını organize etme ve denetleme alışkanlığını geliştirebilirler (Çamlıyer, 1994). Oyun, çocuğun ruhsal gelişiminde ve kişilik kazanmasına olanak sağlayan sevgiden sonraki en önemli etkinliktir (Gürün, 1984).

\section{Yöntem}

\subsection{Araştırma grubu}

$\mathrm{Bu}$ araştırmada; ilkokulun ilk yıllarında 7-8 yaş aralığındaki sosyal uyum ve davranış bozukluğu olan çocuklara verilen kaynaştırılmış ders dışı hareket eğitimi ve oyun etkinliği programının etkisinin iki yıl sonra da devam edip etmediğini incelemek amaçlanmıştır. Araştırma iki aşamalı olarak yürütülmüştür:

Birinci aşamada; Milli Eğitim Bakanlığına bağlı bir ilköğretim okulundan 7-8 yaş arasındaki çocukların arasından okul rehber öğretmeni tarafından sosyal uyum ve davranış bozukluğu olan 25 çocuk ve normal gelişim gösteren 23 çocuk belirlenmiştir. Okul rehber öğretmeninin belirlemiş olduğu sosyal uyum ve davranış bozukluğu olan çocukların içinden, araştırmacı tarafindan basit tesadüfi yöntemle belirlenen 14 çocuk ve normal gelişim gösteren 10 çocukla deney grubu, sosyal uyum ve davranış bozukluğu olan 11 çocuk ve normal gelişim gösteren 13 çocuklada kontrol grubu oluşturulmuştur. Deney grubundaki çocuklara 12 hafta boyunca, hafta da üç (3) gün, bir (1) saat, hareket eğitimi ve oyun etkinliklerinden oluşan bir program uygulanmıştır. Kontrol grubundaki çocuklara ise herhangi bir hareket eğitimi, oyun etkinliği ya da sportif aktivite yaptırılmamıştır. Deney ve Kontrol grubundaki çocukların ailelerine sosyal uyum ve davranış ölçeği çalışmanın başında ön-test ve çalışmanın sonunda son-test olarak uygulanmıştır.

İkinci aşamada; birinci aşamadaki araştırma grubunu oluşturan çocuklardan, iki yıl sonra 9-10 yaşına giren, sosyal uyum ve davranış bozukluğu olan deney grubundan 14 çocuk ve sosyal uyum ve davranış bozukluğu olan kontrol grubundan 11 çocuk olmak üzere toplam 25 çocuğa ( $7 \mathrm{k}$, 18 erkek) ulaşılmış ve araştırma grubunu oluşturan çocuklarla ilgili veriler değerlendirilmiştir.

\subsection{Verilerin toplanmast}

Grupların sosyalleşme düzeylerini belirlemek amacıyla veri toplama aracı olarak "Sosyal Uyum ve Davranış Ölçeği " (AAMD-BS) American Association on Mental Deficiency Adaptive - Behavior Scale gelişimsel özellikler alt başlıklarından biri olan "Sosyalleşme" alanındaki maddeler kullanılmıştır. "Sosyal Uyum ve Davranış Ölçeği”, çocuk ve erişkinlerde günlük yaşam aktivitelerindeki bağımsızlık ve sosyal davranışları değerlendiren standartlaştırılmış bir veri toplama aracıdır (Agrı Ram, 2003). "Sosyal Uyum ve Davranış Ölçeği” "nin Türkçe çevirisi ve geçerlik - güvenirlik çalışması Epir tarafından 1974 yılında yapılmıştır (Bıyıklı, 1987).

\subsection{Verilerin analizi}

Verilerin analizinde frekans ve yüzdeler, ortalama ve standart sapma değerleri belirlenmiştir. Deney ve kontrol grubuna ilişkin izleme testi karşıllaştırmalarda Mann-Whitney U Testi kullanılmıştır. Birinci çalışma sonuçlarının yer aldığı son test ve bu çalışmadan iki yıl sonra uygulanan izleme testi sonuçlarının karşılaştırmasında, puanlar arasındaki farkın anlamlılığını test etmek için Wilcoxon İşaretli Sıralar Testi kullanılmıştır. 
Alp, H., Çamliyer, H. (2015). The children participated with social adjustment disorders fused ..... International Journal of Social Sciences and Education Research, 1 (1), 88-100.

\section{Bulgular ve tartışma}

\subsection{Bulgular}

Tablo 1 incelendiğinde araştırma kapsamına alınan; deney ve kontrol grubundaki çocukların yaş'a göre yüzdelik dağılımları görülmektedir. Tabloya bakıldığında deney ve kontrol grubundaki çocukların 7 ve 8 yaş aralığında yoğunlaştığı ve gruplar arasında istatistiksel olarak anlamlı bir farklı1ık olmadığ görülmektedir $\left(\chi^{2}=, 040 \mathrm{p}=, 841\right)$.

Tablo 1. Deney ve kontrol grubundaki çocukların yaşlara göre dağılımları

\begin{tabular}{lcc}
\multicolumn{1}{c}{ Yaş } & $\mathbf{N}$ & $\mathbf{\%}$ \\
\hline 7 & 12 & .48 \\
\hline 8 & 13 & .52 \\
\hline Toplam & 25 & 100,0
\end{tabular}

Tablo 2. Deney ve kontrol grubundaki çocukların cinsiyete göre dağılımları

\begin{tabular}{lcc} 
Cinsiyet & $\mathbf{N}$ & $\mathbf{\%}$ \\
\hline Erkek & 18 & .72 \\
\hline K1z & 7 & .28 \\
\hline Toplam & 25 & 100,0
\end{tabular}

Tablo 2' ye bakıldığında araştırma kapsamına alınan; deney ve kontrol grubundaki çocukların yaş'a göre yüzdelik dağılımları görülmektedir $\left(\chi^{2}=4,840 \mathrm{p}=, 028\right)$.

Tablo 3.Deney ve kontrol grubundaki çocukların Sosyal Uyum ve Davranış Ölçeği Aile Görüşlerini İçeren İzleme Testi Puanlarına Göre Öntest - Sontest ortalamaları puan dağılımları

\begin{tabular}{|c|c|c|c|c|c|}
\hline & \multirow{2}{*}{$\begin{array}{c}\text { Sosyal Uyum ve } \\
\text { Davranış Ölçeği } \\
\text { Alt Faktörler }\end{array}$} & \multirow{2}{*}{$\mathrm{N}$} & \multicolumn{2}{|c|}{$\bar{x}_{ \pm \mathrm{Ss}}$} & \multirow[b]{2}{*}{ Fark } \\
\hline & & & Öntest & Sontest & \\
\hline \multirow{7}{*}{$\begin{array}{l}\text { Deney } \\
\text { Grubu }\end{array}$} & $\begin{array}{l}\text { İşbirliği Yapa- } \\
\text { bilme }\end{array}$ & \multirow{7}{*}{14} & $1,71 \pm, 469$ & $2,00 \pm, 000$ &, 29 \\
\hline & $\begin{array}{l}\text { Başkalarını Dik- } \\
\text { kate Alma }\end{array}$ & & $7,57 \pm 1,453$ & $8,93 \pm 1,774$ & 1,36 \\
\hline & $\begin{array}{l}\text { Başkalarının Far- } \\
\text { kında Olma }\end{array}$ & & $11,14 \pm 2,381$ & $13,57 \pm 2,344$ & 2,43 \\
\hline & $\begin{array}{l}\text { Başkalarıyla Et- } \\
\text { kileșim }\end{array}$ & & $2,79 \pm, 426$ & $3,00 \pm, 000$ & ,21 \\
\hline & $\begin{array}{l}\text { Grup Faaliyetle- } \\
\text { rine Katılma }\end{array}$ & & $2,07 \pm, 267$ & $2,00 \pm, 000$ &, 07 \\
\hline & Bencillik & & $4,14 \pm 1,406$ & $4,79 \pm, 802$ & ,65 \\
\hline & Sosyal Olgunluk & & $5,71 \pm 1,069$ & $6,00 \pm, 000$ & ,29 \\
\hline \multirow{7}{*}{$\begin{array}{l}\text { Kont- } \\
\text { rol } \\
\text { Grubu }\end{array}$} & $\begin{array}{l}\text { İşbirliği Yapa- } \\
\text { bilme }\end{array}$ & \multirow{7}{*}{11} & $1,00 \pm, 447$ & $1,18 \pm, 405$ & ,18 \\
\hline & $\begin{array}{l}\text { Başkalarını Dik- } \\
\text { kate Alma }\end{array}$ & & $3,09 \pm 1,221$ & $5,27 \pm 1,737$ & ,18 \\
\hline & $\begin{array}{l}\text { Başkalarının Far- } \\
\text { kında Olma }\end{array}$ & & $7,36 \pm 2,420$ & $8,36 \pm 1,567$ & 1,00 \\
\hline & $\begin{array}{l}\text { Başkalarıyla Et- } \\
\text { kileşim }\end{array}$ & & $2,00 \pm 1,000$ & $1,82 \pm, 405$ & ,18 \\
\hline & $\begin{array}{l}\text { Grup Faaliyetle- } \\
\text { rine Katılma }\end{array}$ & & $1,27 \pm, 647$ & $1,36 \pm, 505$ & ,09 \\
\hline & Bencillik & & $2,27 \pm 1,902$ & $2,73 \pm 1,489$ & ,46 \\
\hline & Sosyal Olgunluk & & $3,36 \pm 3,325$ & $4,18 \pm 2,089$ & ,82 \\
\hline
\end{tabular}


Alp, H., Çamlıyer, H. (2015). Kaynaştırılmış ders dışı hareket eğitimi ve oyun etkinliğine katılmış ..... International Journal of Social Sciences and Education Research, 1 (1), 88-100.

Tablo 3'te Deney ve kontrol grubundaki çocukların, sosyal uyum ve davranış ölçeği aile görüşlerini içeren izleme testi puanlarına göre ön-test ve son-test ortalama puan farklarının dağılımları görülmektedir.

Tablo 4. Deney ve kontrol grubundaki çocukların Sosyal Uyum ve Davranış Ölçeği aile görüşlerini içeren izleme testi puanlarına göre Mann-Whitney U Test Sonuçları

\begin{tabular}{|c|c|c|c|c|c|c|c|c|c|c|}
\hline \multirow{3}{*}{$\begin{array}{l}\text { Scsyal Uyum } \\
\text { ve Davranı̧ } \\
\text { Olgeği"ne ait } \\
\text { Alt Fahtörler }\end{array}$} & \multirow{4}{*}{$\begin{array}{l}\text { Grup } \\
\text { Deney } \\
\text { Grubu }\end{array}$} & & \multicolumn{8}{|c|}{ Ailenin Değeriendirmesi } \\
\hline & & & \multicolumn{4}{|c|}{ Ontest } & \multicolumn{4}{|c|}{ Sontest } \\
\hline & & $N$ & $\begin{array}{c}\text { Srra } \\
\text { Ortalamas! }\end{array}$ & $\begin{array}{c}\text { Sura } \\
\text { Toplamı }\end{array}$ & U & P & $\begin{array}{c}\text { Sura } \\
\text { Ortalamas }\end{array}$ & $\begin{array}{c}\text { Sira } \\
\text { Toplamı }\end{array}$ & U & $\mathrm{P}$ \\
\hline \multirow[b]{2}{*}{$\begin{array}{l}\text { İş Birliği } \\
\text { Y̧apabilme }\end{array}$} & & 14 & 16,57 & 232,00 & \multirow[b]{2}{*}{27,000} & \multirow[b]{2}{*}{, 005} & 245,00 & 245,00 & \multirow[b]{2}{*}{14,000} & \multirow[b]{2}{*}{, $000^{\circ *}$} \\
\hline & $\begin{array}{c}\text { Kontrol } \\
\text { Grubu }\end{array}$ & 11 & 8,45 & 93,00 & & & 80,00 & 80,00 & & \\
\hline \multirow{2}{*}{$\begin{array}{l}\text { Bagkalarmi } \\
\text { Dikkate } \\
\text { Alabilme }\end{array}$} & $\begin{array}{l}\text { Deney } \\
\text { Grubu }\end{array}$ & 14 & 18,50 & 259,00 & \multirow[t]{2}{*}{, 000} & \multirow[t]{2}{*}{, 000} & 243,00 & 243,00 & \multirow{2}{*}{16,000} & \multirow{2}{*}{, $000 *$} \\
\hline & $\begin{array}{c}\text { Kontrol } \\
\text { Grubu }\end{array}$ & 11 & 6,00 & 66,00 & & & 82,00 & 82,00 & & \\
\hline \multirow{2}{*}{$\begin{array}{l}\text { Baskalarmun } \\
\text { Farkinda } \\
\text { Olabilme }\end{array}$} & $\begin{array}{l}\text { Deney } \\
\text { Grubu }\end{array}$ & 14 & 17,07 & 239,00 & \multirow[t]{2}{*}{20,000} & \multirow[t]{2}{*}{, 001} & 249,00 & 249,00 & \multirow[t]{2}{*}{10,000} & \multirow[t]{2}{*}{, $000 *$} \\
\hline & $\begin{array}{c}\text { Kontrol } \\
\text { Grubu }\end{array}$ & 11 & 782 & 86,00 & & & 76,00 & 76,00 & & \\
\hline \multirow{2}{*}{$\begin{array}{l}\text { Baskaları ile } \\
\text { Ethileşim } \\
\text { Kurabilme }\end{array}$} & $\begin{array}{l}\text { Deney } \\
\text { Grubu }\end{array}$ & 14 & 15,64 & 219,00 & \multirow[t]{2}{*}{40,000} & \multirow[t]{2}{*}{, 044} & 259,00 & 259,00 & \multirow[t]{2}{*}{, 000} & \multirow[t]{2}{*}{, $000 *$} \\
\hline & $\begin{array}{c}\text { Kontrol } \\
\text { Grubu }\end{array}$ & 11 & 9,64 & 106,00 & & & 66,00 & 66,00 & & \\
\hline \multirow{2}{*}{$\begin{array}{l}\text { Grup } \\
\text { Faaliyetierine } \\
\text { Katılabime }\end{array}$} & $\begin{array}{l}\text { Deney } \\
\text { Grubu }\end{array}$ & 14 & 16,64 & 233,00 & \multirow{2}{*}{26,000} & \multirow[t]{2}{*}{, 004} & 231,00 & 231,00 & \multirow{2}{*}{28,000} & \multirow{2}{*}{, $006^{* *}$} \\
\hline & $\begin{array}{c}\text { Kontrol } \\
\text { Grubu }\end{array}$ & 11 & 836 & 92,00 & & & 94,00 & 94,00 & & \\
\hline \multirow[t]{2}{*}{ Bencillik } & $\begin{array}{l}\text { Deney } \\
\text { Grubu }\end{array}$ & 14 & 16,00 & 224,00 & \multirow[t]{2}{*}{35,000} & \multirow[t]{2}{*}{, 021} & 233,00 & 233,00 & \multirow[t]{2}{*}{26,000} & \multirow[t]{2}{*}{, $004^{* *}$} \\
\hline & $\begin{array}{c}\text { Kontrol } \\
\text { Grubu }\end{array}$ & 11 & 9,18 & 101,00 & & & 92,00 & 92,00 & & \\
\hline Sogyal & $\begin{array}{l}\text { Deney } \\
\text { Grubu }\end{array}$ & 14 & 15,21 & 213,00 & 46,000 &, 095 & 217,00 & 217,00 & 42,000 &, 058 \\
\hline Olgunluk & $\begin{array}{c}\text { Kontrol } \\
\text { Grubu }\end{array}$ & 11 & 10,18 & 112,00 & & & 108,00 & 108,00 & & \\
\hline
\end{tabular}

Tablo 4' e bakıldığında sosyal uyum ve davranış ölçeği izleme testi sonuçlarına göre deney grubunun; Sosyal Olgunluk faktör puanı hariç, İşbirliği Yapabilme, Başkalarını Dikkate Alma, Başkalarının Farkında Olabilme, Başkalarıyla Etkileşim, Grup Faaliyetlerine Katılma, Bencillik, faktör puanlarının kontrol grubundaki çocuklardan yüksek olduğu ve istatiksel olarak anlamlı bir fark olduğu görülmüştür $(\mathrm{p}<0.01)$.

Sonuçlara göre; deney grubundaki çocukların izleme test puanlarının kontrol grubundaki çocukların izleme test puanlarından yüksek çıkmasında uygulanan kaynaştırılmış ders dışı hareket eğitimi ve oyun etkinlikleri programının iki yıl sonrada etkisini sürdürdüğ̈ söylenebilir. 
Alp, H., Çamliyer, H. (2015). The children participated with social adjustment disorders fused ..... International Journal of Social Sciences and Education Research, 1 (1), 88-100.

Tablo 5. Deney grubundaki çocukların Sosyal Uyum ve Davranış Ölçeği aile görüşlerini içeren Son-Test İzleme Testi Puanlarına Göre Wilcoxon İşaretli Sıralar Test sonuçları

\begin{tabular}{|c|c|c|c|c|c|c|}
\hline \multirow{2}{*}{$\begin{array}{l}\text { Sosyal Uyum ve } \\
\text { Davranış Ölçeği } \\
\text { Alt Faktörler }\end{array}$} & \multirow[b]{2}{*}{$\mathrm{N}$} & \multicolumn{3}{|c|}{ Ön-test ve Son-test } & \multirow[b]{2}{*}{$\mathrm{Z}$} & \multirow[b]{2}{*}{$\mathrm{P}$} \\
\hline & & Sira & $\begin{array}{c}\text { Sira Ortala- } \\
\text { mas } 1\end{array}$ & $\begin{array}{l}\text { Sira Top- } \\
\text { lamı }\end{array}$ & & \\
\hline \multirow{3}{*}{$\begin{array}{l}\text { İş Birliği Yapa- } \\
\text { bilme }\end{array}$} & 0 & Negatif Sira &, 00 &, 00 & \multirow{3}{*}{$-2,00$} & \multirow{3}{*}{, 046} \\
\hline & 4 & Pozitif Sira & 2,50 & 10,00 & & \\
\hline & 10 & Eşit & - & - & & \\
\hline \multirow{3}{*}{$\begin{array}{l}\text { Başkalarını Dik- } \\
\text { kate Alabilme }\end{array}$} & 0 & Negatif Sira &, 00 &, 00 & \multirow{3}{*}{$-2,460$} & \multirow{3}{*}{, 014} \\
\hline & 7 & Pozitif Sira & 4,00 & 28,00 & & \\
\hline & 7 & Eşit & - & - & & \\
\hline \multirow{3}{*}{$\begin{array}{l}\text { Başkalarının Far- } \\
\text { kında Olabilme }\end{array}$} & 0 & Negatif Sira &, 00 &, 00 & \multirow{3}{*}{$-2,972$} & \multirow{3}{*}{, 003} \\
\hline & 10 & Pozitif Sira & 5,50 & 55,00 & & \\
\hline & 4 & Eşit & - & - & & \\
\hline \multirow{3}{*}{$\begin{array}{l}\text { Başkalarıyla Etki- } \\
\text { leşim }\end{array}$} & 0 & Negatif Sira &, 00 &, 00 & \multirow{3}{*}{$-1,732$} & \multirow{3}{*}{, 083} \\
\hline & 3 & Pozitif Sira & 2,00 & 6,00 & & \\
\hline & 11 & Eşit & - & - & & \\
\hline \multirow{3}{*}{$\begin{array}{l}\text { Grup Faaliyetle- } \\
\text { rine Katılabilme }\end{array}$} & 1 & Negatif Sira & 1,00 & 1,00 & \multirow{3}{*}{$-1,000$} & \multirow{3}{*}{, 317} \\
\hline & 0 & Pozitif Sira &, 00 &, 00 & & \\
\hline & 13 & Eşit & - & - & & \\
\hline \multirow{3}{*}{ Bencillik } & 0 & Negatif Sira &, 00 &, 00 & \multirow{3}{*}{$-1,732$} & \multirow{3}{*}{, 083} \\
\hline & 3 & Pozitif Sira & 2,00 & 6,00 & & \\
\hline & 11 & Eşit & - & - & & \\
\hline \multirow{3}{*}{ Sosyal Olgunluk } & 0 & Negatif Sira &, 00 &, 00 & \multirow{3}{*}{$-1,000$} & \multirow{3}{*}{, 317} \\
\hline & 1 & Pozitif Sira & 1,00 & 1,00 & & \\
\hline & 13 & Eşit & - & - & & \\
\hline
\end{tabular}

Tablo 5'e bakıldığında sosyal uyum ve davranış ölçeği izleme testi sonuçlarına göre deney grubunun; İşbirliği, Başkalarını Dikkate Alma, faktör puanlarının yüksek olduğu ve istatiksel olarak anlamlı bir fark olduğu görülmüştür $(\mathrm{p}<0,05)$. Başkalarının Farkında Olabilme faktör puanın yükseldiği ve istatiksel olarak anlamlı bir fark görülmektedir $(\mathrm{p}<0,01)$. Başkalarıyla Etkileşim, Grup Faaliyetlerine Katılma, Bencillik ve Sosyal Olgunluk faktör puanları arasında istatiksel olarak anlamlı bir fark olmadığı görülmektedir ( $>00.05)$. 
Alp, H., Çamlıyer, H. (2015). Kaynaştırılmış ders dışı hareket eğitimi ve oyun etkinliğine katılmış ..... International Journal of Social Sciences and Education Research, 1 (1), 88-100.

Tablo 6. Kontrol grubundaki çocukların Sosyal Uyum ve Davranış Ölçeği aile görüşlerini içeren Son-Test İzleme Testi Puanlarına Göre Wilcoxon İşaretli Sıralar Test sonuçları

\begin{tabular}{|c|c|c|c|c|c|c|}
\hline \multirow{3}{*}{$\begin{array}{l}\text { Sosyal Uyum ve } \\
\text { Davranış Ölçeği } \\
\text { Alt Faktörler }\end{array}$} & \multirow[b]{3}{*}{$\mathrm{N}$} & \multicolumn{3}{|c|}{ Kontrol Grubu } & \multirow[b]{3}{*}{$\mathrm{Z}$} & \multirow[b]{3}{*}{$\mathrm{P}$} \\
\hline & & \multicolumn{3}{|c|}{ Ön-test ve Son-test } & & \\
\hline & & Sira & $\begin{array}{c}\text { Sira Ortala- } \\
\text { mas1 }\end{array}$ & $\begin{array}{c}\text { Sira Top- } \\
\text { lamı }\end{array}$ & & \\
\hline \multirow{3}{*}{$\begin{array}{l}\text { İş Birliği Yapa- } \\
\text { bilme }\end{array}$} & 0 & Negatif Sira &, 00 &, 00 & \multirow{3}{*}{$-1,414$} & \multirow{3}{*}{, 157} \\
\hline & 2 & Pozitif Sira & 1,50 & 3,00 & & \\
\hline & 9 & Eşit & - & - & & \\
\hline \multirow{3}{*}{$\begin{array}{l}\text { Başkalarını Dik- } \\
\text { kate Alabilme }\end{array}$} & 1 & Negatif Sira & 2,50 & 2,50 & \multirow{3}{*}{$-1,994$} & \multirow{3}{*}{,046 } \\
\hline & 6 & Pozitif Sıra & 4,25 & 25,50 & & \\
\hline & 4 & Eşit & - & - & & \\
\hline \multirow{3}{*}{$\begin{array}{l}\text { Başkalarının Far- } \\
\text { kında Olabilme }\end{array}$} & 0 & Negatif Sira &, 00 &, 00 & \multirow{3}{*}{$-1,841$} & \multirow{3}{*}{,066 } \\
\hline & 4 & Pozitif Sura & 2,50 & 10,00 & & \\
\hline & 7 & Eşit & - & - & & \\
\hline \multirow{3}{*}{$\begin{array}{l}\text { Başkalarıyla Et- } \\
\text { kileşim }\end{array}$} & 4 & Negatif Sira & 3,50 & 14,00 & \multirow{3}{*}{,- 816} & \multirow{3}{*}{,414 } \\
\hline & 2 & Pozitif Sıra & 3,50 & 7,00 & & \\
\hline & 5 & Eşit & - & - & & \\
\hline \multirow{3}{*}{$\begin{array}{l}\text { Grup Faaliyetle- } \\
\text { rine Katılabilme }\end{array}$} & 1 & Negatif Sira & 2,00 & 2,00 & \multirow{3}{*}{,- 577} & \multirow{3}{*}{, 564} \\
\hline & 2 & Pozitif Sira & 2,00 & 4,00 & & \\
\hline & 8 & Eşit & - & - & & \\
\hline \multirow{3}{*}{ Bencillik } & 0 & Negatif Sira &, 00 &, 00 & \multirow{3}{*}{$-1,633$} & \multirow{3}{*}{, 102} \\
\hline & 3 & Pozitif Sıra & 2,00 & 6,00 & & \\
\hline & 8 & Eşit & - & - & & \\
\hline \multirow{3}{*}{ Sosyal Olgunluk } & 0 & Negatif Sira &, 00 &, 00 & \multirow{3}{*}{$-1,604$} & \multirow{3}{*}{, 109} \\
\hline & 3 & Pozitif Sura & 2,00 & 6,00 & & \\
\hline & 8 & Eşit & - & - & & \\
\hline
\end{tabular}

Tablo 6'ya bakıldığında sosyal uyum ve davranış ölçeği izleme testi sonuçlarına göre kontrol grubunun; İşbirliği Yapabilme, Başkalarını Dikkate Alma, Başkalarının Farkında Olabilme, Başkalarıyla Etkileşim, Grup Faaliyetlerine Katılma, Bencillik ve Sosyal Olgunluk faktör puanları arasında istatiksel olarak anlamlı bir fark olmadığı görülmektedir ( $>0.05)$.

\section{Tartışma}

Hareket eğitimi, çocuğun duyu organları yoluyla dış dünyadan topladığı duyumları (informasyonları) değerlendirip psikomotor tepki ve davranış olarak kendini ortaya koyduğu süreçlerde çok etkilidir (Çamlıyer 1994). İyi planlanmış bir hareket eğitimi programı ile çocuklar diğer çocukların farkına varma, onlarla uyum içerisinde hareket etme ve işbirliği kurma yeteneğini geliştirebilirler (Özlü-Fazlığlu, Baran, 2004). Fiziksel aktivite programlarının otizmli çocukların problem davranışlarda azalma, büyük fiziksel ve eğlence aktivitesinin yanı sıra, fiziksel uygunluk düzeyindeki artışa neden olabileceğini göstermiştir (Connor, French \& Henderson, 2000). Piek ve Dyck, davranış problemi olan çocukların, gelişim seviyesine uygun fiziksel aktivitelerin, günlük yaşam içerisine yerleştirilmesi gerektiğini vurgulamaktadırlar (Akt. Yanardağ, 2007). Fiziksel 
Alp, H., Çamliyer, H. (2015). The children participated with social adjustment disorders fused .....

International Journal of Social Sciences and Education Research, 1 (1), 88-100.

aktivite gerilim ve anksiyetenin boşalmasına yardım eder ve emosyonel stabilite ve sabır davranışını kolaylaştırır (Baltacı, 2008). Hareket eğitimi ve sportif etkinlikler, öğretilebilir zihinsel engelli çocukların sosyalleşmeleri üzerinde etkili olduğu ve spor ile sosyalleşme arasında manidar bir ilişkinin olduğu gözlemlenmiştir (Demirağ, 2010). Hareket eğitimi ve spor, sağlıklı bir kişilik yapısının oluşumunda etkin bir rol oynamakta ve genç bireylerin fiziksel, duygusal ve toplumsal bakımdan sağlıklı kişilik gelişimleri, karşılıklı dayanışmanın sağlanması ve toplum üyeliğinin kazanılmasında büyük önem taşımaktadır (Uslu ve Hasırc1, 1999; Demirağ, 2010; Aksoy, Bakış ve Ünveren, 2012; Çamlıyer ve Çamlıyer, 2011).

Çocukların sosyal beceri kazanmalarında önemli olan iki beceriden biri oyun diğeri ise yaşıtları ile iletişim kurmadır (Rubin ve Diğ., 1983). Oyun, bir yandan çocuğun fiziksel ve zihinsel yapısını geliştirirken, diğer yandan da onun nesneler dünyasıyla ilişki kurmasını, özgürlük ve bireysellik kazanmasını sağlayan, daha sonra da toplumsallaşmasına büyük ölçüde yardımcı olan çok önemli bir etkinliktir (Gürün, 1984). Çocuk oyun aracılığıyla duygusal yönden rahatlar ve çevresindeki bireylerle ilişkisinde kendisine düşen rolü oynayarak kişilik gelişimini sürdürür (Arslan, 2000). Oyun bir yandan çocuğun gelişimine katkıda bulunurken, öte yandan eğitici bir değere sahiptir. Bir yandan izleyen yetişkine çocuğun kişilik özellikleriyle ilgili önemli ipuçları verirken, bir yandan da çocuk için tedavi edici özelliğe sahip bir etkinliktir (Yavuzer, 2005). Oyunla çocuk, duygusal tepkilerini denetim altına almayı, sorunlarından uzaklaşmayı, kendine güveni sevinç ve haz almayı sevgi ve beğenilme duygularını geliştirir. Buda duygusal gelişim için önemli bir katkıdır. Yine oyunla çocuk eski Uygulama imlerini, davranışlarını beğenilerini zenginleştirir. Nesneler arasındaki ayrılık ve benzerlikleri kavrar, düşünme, kavrama, algılama gibi zihinsel yeteneklerini geliştirir (Akandere, 2003). Oyun çocuklarda birlik olma, başkasına yardım etme, güçsüzü koruma, haklıdan yana olma, hakkına razı olma duygularını geliştirir. Çocuk görgü kurallarını, çevresindeki canlıları korumayı, onlara zarar vermemeyi oyunda uygular (Milli Eğitim Bakanlığı (MEB), 2006).

Oyun, çocuğun ders çalışması kadar önemlidir. Çocuklar, çevrelerinde gördükleri uğraş ve becerileri oyunlarında canlandırır, dener ve uygularlar. Gelecekte yaşayacakları rolleri (annelik, babalık vb.), karşılaşacakları olaylar karşısında nasıl davranmaları gerektiğini oyunlarda yaşayarak öğrenirler (Karakaya, 2007). Oyun yoluyla sosyalleşen çocuk, ben ve başkası kavramlarının bilincine varır. Vermeyi ve almayı da o yun aracılığıyla öğrenir (Yavuzer 1999, Akt. Temür, 2007). Oyun becerileri sosyal iletişimi gerektiren en önemli etkinliklerden biridir. Çocuklar bebeklik dönemlerinden itibaren etkinlikleri sırasında akranlarıyla sosyal iletişim kurarlar (Klein, Cook ve Richardson-Gibbs, 2001, Akt. Batu,2011). Fiziksel aktivite ve oyun ile ilgilenmenin, çocuklarda akademik başarıyı arttırdığı, psikolojik olarak iyi olma hali sağladığı, depresyon ve kaygı bulgularını azalttığı, kendine saygıyı arttırarak, çocukların daha atılgan olmalarını sağlamaya katkı yaptı̆̆ belirlenmiştir (Çavdar, 2011; Strong ve ark. 2005; Taylor ve ark., 1985; Kirkcaldy ve ark., 2002; Penedo ve Dahn, 2005; Parfitt ve Eston, 2005; Suitor ve Kraak, 2007). Oyun ve sporun toplumsallaştırıcı etkisi, bireyi başkalarıyla ve toplumla barışık, onlarla uyumlu ve dengeli bir yapıya ulaşmasını sağlayacak ön koşulları hazırlamaktır (Akt. Taşkıran ve arkd., 2014). Sportif etkinlikler ve oyun, büyük önem verilen birçok sosyal değerin oluşmasına sürekli hale gelmesine yardımcı olur. İnsanlar onlara uygun olan sosyal rolleri öğrenirler, hemen tüm insanlar çocukken oyun, spor ve diğer aktiviteler ile sosyalleşirler (Yetim, 2011; Küçük ve Koç, 2014). 
Alp, H., Çamlıyer, H. (2015). Kaynaştırılmış ders dış1 hareket eğitimi ve oyun etkinliğine katılmış ..... International Journal of Social Sciences and Education Research, 1 (1), 88-100.

Kaynaştırma ortamında normal çocukların özürlü sınıf arkadaşlarının çeşitli alanlarda gelişimini sağlamada davranış modelleri olarak görev yaptıkları belirtilmiştir Yine aynı araştırmada kaynaştırma programında normal çocukların özürlü çocuklara sınırlı olan beceri ve yeteneklerini geliştirmede takviye edici etmen olarak ifade edilmiştir (Metin, 1992). Engelli çocuklar kaynaştırmayla, sosyal ve eğitimsel yaşamda akranları ile birlikte olabilme, onları model alarak daha geniş bir toplum tarafından benimsenen davranış repertuarı ve repertuar içinde yer alan becerileri geliştirebilme ve öğrendikleri yeni davranışları uygulama fırsatını elde ederler. Bunun sonucunda engelli bireyin toplum tarafından dışlanmasına neden olan tipik engelli davranışlarının azalması sağlanacak ve çocuğun soysal kabulü, uyumu ve etkileşimi artacaktır (Kuz, 2001). Kaynaştırma eğitimine katılan normal gelişim gösteren çocuklar ve engelli çocuklar arasında olumlu sosyal etkileşim, engelli çocuğa akranlarıyla ilişki kurabilmeyi ve bu ilişkiyi devam ettirebilmek için gerekli olan deneyimleri kazanmasına yardımcı olmaktadır" (Karamanlı 1998, Akt. Temür, 2007).

\section{Sonuç ve öneriler}

İlkokul birinci ve ikinci sınıfa devam eden 7-8 yaşındaki sosyal uyum bozukluğu olan çocuklara uygulanan kaynaştırılmış ders dışı hareket eğitimi ve oyun etkinlikleri programının, uygulandıktan iki yıl sonra çocukların sosyal uyum süreçleri üzerindeki etkisinin devam edeceği yönündeki hipotezin araştırıldığg çalışmada; kaynaştırılmış ders dışı hareket eğitimi ve oyun etkinlikleri programı verilen deney grubundaki çocukların, sosyal uyum ve davranış ölçeği test puanlarının kontrol grubundaki çocukların test puanlarına göre yüksek olduğu, iki grubun puanları arasında istatistiksel olarak anlamlı bir fark olduğu görülmüştür.

Deney grubundaki çocukların sosyal uyum ve davranış ölçeği alt faktörlerinden sosyal olgunluk faktör puanının da bir fark olduğu fakat bu farkın istatistiksel olarak anlamlı olmadığı, bu faktörün dışındaki tüm faktör test puanlarının kontrol grubundaki çocukların test puanlarına göre yüksek olduğu ve istatiksel olarak test puanları arasında anlamlı bir fark olduğu görülmüştür (Bakinız Tablo 4).

Deney grubundaki çocukların iki yıl sonraki sosyal uyum süreçlerindeki gelişimin devamlılık göstermesinde uygulanan kaynaştırılmış ders dışı hareket eğitimi ve oyun etkinlikleri programının etkisinin olduğu söylenebilir.

Hareket eğitimi ve oyun etkinlikleri doğal ortamı içinde bulunan tüm bireyleri farklı şekillerde etkilemekte ve tüm gelişim boyutlarını destekleyebilmektedir. Bu çalışma sonucunda, hareket eğitimi ve oyun etkinliklerinin özellikle sosyal uyum problemi olan çocukların sosyalleşmeleri aşamasında önemli bir etken olduğu belirgindir bu nedenle okul öncesi ve ilköğretim çağındaki çocukların eğitimlerinde onların gelişimlerini destekleyici oyun etkinliklerine daha fazla yer verilmelidir.

\section{Kaynakça}

Ağrı Rehberlik ve Araştırma Merkezi, (2003). Özel Eğitim ve Kaynaştırma Uygulamaları. www. agrıram. org .tr, web adresi, 2007, pp: 98-103.

Akandere, M., (2003). Eğitici Okul Oyunları. Ankara: Nobel Yayın Dağıtım, pp: 1-2, 8, 12-13, 15.

Aksoy, R., Bakış, M. \& Ünveren, M., (2012). Spor sosyolojisi. Ankara, Milli Eğitim Bakanlığı, Devlet Kitaplar1, Üçüncü Bask1, , ISBN 978-975-11-3334-2. 
Alp, H., Çamliyer, H. (2015). The children participated with social adjustment disorders fused ..... International Journal of Social Sciences and Education Research, 1 (1), 88-100.

Arslan, Ü., (2007). Okul Öncesi Eğitimde Temel Becerilerin ve Sosyal Davranışların Kazandırılması. Gülengül Haktanır (Ed.), Okul Öncesi Eğitime Giriş, Ankara: Anı Yayıncılık, pp:205-230.

Azaula, M., Msall, M.E., \& Buck, G. (2000). Measuring functional status and family support in schoolaged children with Cerebral Palsy, Comparison of three instruments. Arch Phys Med, 81: 307- 311.

Bayhan, P.S., \& Diğerleri., (2005). Engelli Ergenlerin Sosyalleşmelerini Etkileyen Etmenler. Çăg daş Ĕ̆gitim Dergisi, Yıl: 30, sayı 319, pp: 11.

Baltacı, G., (2008). Çocuk ve Spor. Ankara: Hacettepe Üniversitesi - Sağllk Bilimleri Fakültesi, Fizik Tedavi ve Rehabilitasyon Bölümü, Birinci Basım, Sağlık Bakanlı̆̆ı Yayın No: 730, ISBN: 978-975-590246-3, pp:3.

Batu, S., (2011). 0-6 Yaş Arası Down Sendromlu Çocuklar ve Gelişimleri. Ankara: Kök Yayıncılık, 2. Baskl, pp:285.

Bıyıklı, L., (1987). Yetiştirme yurtlarındaki çocukların zihinsel ve psiko-sosyal gelişimlerinin incelenmesi. Ankara Üniversitesi Eğitim Bilimleri Fakültesi Dergisi, Cilt: 20, Sayı: 1

Bilen, M., (1994). Ailede Toplumsallaşma, Aile ve Eğitim. Türk Ĕ̆itim Derneği XVIII. Eğitim Toplantısı, 20-21 Ekim, Ankara: Şafak Matbaacılık, s. 62-74. ISBN 975 • 7583-04-9.

Çağlar, D., (1981). Uyumsuz Çocuklar - Ĕ̆gitim. Ankara: Ankara Üniversitesi Basımevi, 1981.

Çamlıyer, H., \& Çamlıyer, H., (2011). Çocuk Hareket Eğitimi ve Oyun, Manisa, Can Ofset, pp: 116-117122.

Çamlıyer, H., (1994). Eğitilebilir Zeka Düzeyindeki Çocuklarda Hareket Eğitiminin Algısal Gelişim Düzeylerine Etkileri. İzmir, Yayınlanmamış Doktora Tezi, pp: 1.

Çavdar, B., (2011). Öğretilebilir Zihinsel Engelli Öğrencilerde Beden Ĕğitimi Ve Spor Aktivitelerinin Toplumsallaşma Düzeylerine Etkisi. İzmir, Yayınlanmamış Yüksek Lisans Tezi, pp: 60.

Connor, J., French, R., \& Henderson, H., (2000). Use of physical activity to improve behaviour of children with autism- Two for one benefits. Palaestra, 16(3):22.

Demirdağ, M., (2010). Sporun Öğretilebilir Zihinsel Engelli Çocukların Sosyalleşmeleri Üzerine Etkisi. Kütahya: Dumlupınar Üniversitesi Sağllk Bilimleri Enstitüsü Yüksek Lisans Tezi, pp: 127.

Gallahue L.D, (1976). Motor Development and Movement Experiences for Young Children. Newyork, John Wiley and Sons, Inc, 1976, pp: 261 Indiana, ISBN 0-471-29042-4.

Gürün, O. A., (1984). Çocuğumuzu Tanıyalım, İstanbul, İnkılâp Yayınevi.

Karakaya N., (2007). İlköğretimde Drama ve Örnek Bir Uygulama. Gazi Eğitim Fakültesi Dergisi, Cilt 27, Sayı: 1, pp: 103-139.

Kocayörük, A., (2000). İlköğretim Öğrencilerinin Sosyal Becerilerini Geliştirmede Dramanın Etkisi. Ankara, Yayımlanmamış Yüksek Lisans Tezi, 2000, pp:1.

Kirkcaldy, B.D., Shephard, R.J. \& Siefen, R.G., (2002). The relationship between physical activity and selfimage and problem behaviour among adolescents. Soc Psychiatry Psychiatr Epidemiol, 37(11): 544-50.

Kuz, T., (2001). Kaynaştırma Eğitimine Yönelik Tutumların İncelenmesi. Ankara, Özürlüler İdaresi Başkanlı̆̆ Yayınları / 17, pp:1, 9-10, 15-20, 30-35, 42.

Küçük H., \& Koç H., (2014). Psiko-Sosyal Gelişim Süreci İçerisinde İnsan ve Spor İlişkisi. birimler.dpu.edu.tr/app/views/panel/137-141.pdf.

Mark W., \& Jan S. W., (1995). Including Children With Special Needs in Early Childhood Programs. Editor: Mark Wolary ve Jan S. Wilbers. (Second Edition). NAEYC, Washington, ,pp:8-9. 
Alp, H., Çamlıyer, H. (2015). Kaynaştırılmış ders dışı hareket eğitimi ve oyun etkinliğine katılmış ..... International Journal of Social Sciences and Education Research, 1 (1), 88-100.

Metin, N., (1992). Okul Öncesi Dönemde Özürlü Çocuklar İçin Kaynaştırma Programları. Özel Eğitim Dergisi. 1992-112, pp: 34 -36.

Milli Ĕ̆itim Bakanlığı (MEB) (2006). Eğitsel Oyunlar Dairesi Öğretim Programı. Ankara, 2006, pp:5-7.

Nancy, D. B., (1986). The Effects of Classroom Organization on Mainstreamed Preschool Children. Exceptional Children. Cilt:52, Sayl:5, , pp.425-434.

Özdemir, S., (2014). Özel Ĕgitime Gereksinimi Olan Öğrenciler ve Özel Eğitim. Editör; Diken, İ.H., Ankara - 9. Bask1: Pegem Akademi, pp:382.

Özlü-Fazlığlu, Y. \& Baran, G., (2004). Duyusal Entegrasyon Programının Duyusal ve Davranış Problemleri Üzerine Etkisi. Ankara Üniversitesi Basımevi.

Özer S. \& Özer K., (2002). Çocuklarda Motor Gelişim. İstanbul, Atlas yayın dağı̆tım, 2.Basım, 2002, pp 21, 225-227.

Parfitt, G. \& Eston, R.G., (2005). The relationship between children's habitual activity level and psychological well-being. Acta Paediatr, 94(12):1699-701.

Penedo, F.J. \& Dahn, J.R., (2005). Exercise and well-being: A review of mental and physical health benefits associated with physical activity. Curr Opin Psychiatry, 18(2): 189-93.

Rubin, K.H., Fein, G.G, \& Vanderbeg,B.,(1983). Handbook of child Psychology. NevYork:, Willey, pp: 7986.

Strong, W.B., Malina, R.M., Blimkie, C.J., Daniels, S.R., Dishman, R.K., Gutin, B., Hergenroeder, A.C., Must, A., Nixon, P.A., Pivarnik, J.M., Rowland, T., Trost, S., Trudeau, F., (2005). Evidence based physical activity for school-age youth. Journal Pediatrics, 146(6), 732-737.

Suitor, C.W. \& Kraak, V.I., (2007). Adequacy of evidence for physical activity guidelines development: workshop summary. Institute of Medicine. Washington, DC: National Academies Press.

Taşkıran C., Selçuk, M., H., \& Doğar, Y., (2014). Beden Eğitimi Dersinin Sosyalleşmeye Olan Etkisine İlişkin İlköğretim Öğrenci Velilerinin Görüşleri. The Journal of Academic Social Science Studies, Number: 26, pp: 159-166, Summer II 2014.

Taylor, C.B., Sallis, J.F. \& Needle, R., (1985). The relation of physical activity and exercise to mental health. Public Health Rep, 100(2): 195-211.

Temür, E. (2007). Polimetrik Ve Direnç Egzersizlerinin, Zihinsel Engelli Çocukların (10-15 Yaş) Kol ve Bacak Güç-Kuvvet Gelişimlerine Etkisinin İncelenmesi. Kırıkkale Üniversitesi Sağllk Bilimleri Enstitüsü Beden Eğitimi ve Spor Anabilim Dalı Yüksek Lisans Tezi, Kırıkkale, pp: 21-22.

Tolan B., (1996). Toplum Bilimlerine Giriş. Ankara, Adım Yayıncılık.

Tony B., (1987). Integrating Special Education. Editor: Tony Booth ve Patricia Potts. (Third Edition). Basil Blackwell Ltd., Oxford, pp:3.

Uslu, A. \& Hasırcı, S., (1999). Lise ve Dengi Okullarda Öğrenim Gören Öğrencilerin Beden Eğitimi Derslerinin Sosyal Uyum Düzeyine Etkilerinin Araştırılması. Manisa: Beden Eğitimi ve Spor Bilimleri Dergisi, pp:3-4.

Yanardağ, M., (2007). Otistik Çocuklarda Farklı Egzersiz Uygulamalarının Motor Performans ve Sterotip Davranışlar Üzerine Etkileri. Ankara: Hacettepe Üniversitesi, Spor Fizyoterapistliği Programı Doktora Tezi.

Yavuzer, H., (2005). Çocuğu Tanımak ve Anlamak. İstanbul, Remzi Kitabevi, pp:64,69.

Yetim, A. (2011). Sosyoloji ve Spor. Ankara: Berikan Yayınevi, ISBN: 9752673571. 
Alp, H., Çamliyer, H. (2015). The children participated with social adjustment disorders fused .....

International Journal of Social Sciences and Education Research, 1 (1), 88-100.

\section{Extended abstract in English}

Socializing, learning and cultural values prevailing in the individual's community, adult means can be brought to apply to life situations and adult behavior preparing the world. Some children have difficulty understanding others and because of the adjustment problems they have, fall into dispute, they exhibit different behaviors and may adversely affect both themselves and the environment. Education enter the individual's socialization process in the circuit, the society in which it helps the social interaction between individuals. Education and well-planned act play activities helps to reach the child's other children noticed and acting in compliance with them, and develop the ability to cooperate.

In this study; aimed to examine the effects two years after the implementation of social adaptation of children movement education applied fused extracurricular activities and games program. The study was conducted in two phases. In the first stage; From a primary school attached to the Ministry of Education by the social cohesion and behavioral disorders among children between 7-8 years of school guidance counsellors and 25 children showing normal development of 23 children it has been identified. Through the children with social adaptation and behavioral disorders as determined by the school guidance counsellor, as determined by simple random method by researchers 14 children and normal development of 10 children in the experimental group, with social cohesion and behavioral disorders 11 children and control 13 in çocukla normal development group has been formed. Children in the experimental group for 12 weeks, week three (3) days, one (1) hour, a program of movement education and play activities were implemented. If any movement of children in the control group training, game activities or sporting activity is not built. At the beginning of the families of children working in the scale of social adjustment and behavior experiment and control group was administered a pre-test and post-test at the end of the study. In the second stage; children constitute the group of research in the first phase, within the 9-10 age two years later, social cohesion and the experimental group behavior disorder which 14 children and social harmony and conduct disorder than the control group of 11 children for a total of 25 children ( 7 girls, 18 boys) reached and data relating to children form the research group was evaluated. Measurement as a means social adaptive and behavior scale is used who developed by the adaptive behavior scale for elementary school children Epirus (1974). Social adaptation process were compared 9-10 years of age in the 7-8 age range of with social adaptation in children. In analyzing the data, Mann-Whitney-U test and Wilcoxon Signed Ranks Test was used.

According to the scale of the experimental group behavior, social cohesion and tracking test results; Excluding social maturity factor scores, to make cooperation, taking into account the others, others able to be aware, interaction with others, participation in group activities, selfishness, which is higher than children in the factor scores of the control group and showed that statistically there was a significant difference $(\mathrm{p}<0.01)$. According to the scale of the experimental group behavior, social cohesion and tracking test results; cooperation, taking into account the others, and was found to be higher factor scores was statistically significant difference $(p<0.05)$. Others to be aware of the rise of the factor scores and statistically significant difference was observed ( $p$ $<0.01$ ). Interaction with other group participation activity, it appears that there is no statistically significant difference between selfishness and social maturity factor scores ( $p>0.05)$. The control group, according to the scale of social cohesion and behavior tracking test results; The cooperation can take account of others, able to be aware of others, interaction with others, the group 
Alp, H., Çamlıyer, H. (2015). Kaynaştırılmış ders dışı hareket eğitimi ve oyun etkinliğine katılmış International Journal of Social Sciences and Education Research, 1 (1), 88-100.

participate in the activities, it appears that no statistically significant difference between selfishness and social maturity factor scores $(\mathrm{p}>0.05)$.

\section{Result and Recommendations}

Primary school first and second grade ongoing 7-8 year-old social adjustment disorder in children applied fused extracurricular motion training and games activities program, two years after the implementation of children's social adaptation on the study investigated the hypothesis that it would continue in effect; children in fused extracurricular movement education and play activities experimental group the program, the children in the control group of social cohesion and behavior scale test scores was higher than on test scores was found to be a statistically significant difference between the scores of the two groups. Fused extracurricular applied to the children in the experimental group showed continuity of the development process in motion two years of education and social cohesion can be said that the impact of gaming activities program.

Movement education and gaming activities in a natural environment in which all individuals are affected in different ways and can support all aspects of development. The study concludes, movement education and the children's socialization stage, which is particularly social adjustment problems of gaming activities is obvious that a significant factor therefore in the education of children in pre-school and primary school age should be given more room to support play activities for their development. 